\title{
Determination of the age distribution of primary and secondary aerosol species using a chemical transport model
}

\author{
Kristina M. Wagstrom ${ }^{1}$ and Spyros N. Pandis ${ }^{1,2}$ \\ Received 22 January 2009; revised 23 April 2009; accepted 5 May 2009; published 23 July 2009.
}

[1] A computationally efficient scheme to allow tracking of aerosol species age as a function of space and time within a three-dimensional chemical transport model (CTM) has been developed. The aerosol age distribution is calculated by utilizing the Particulate Matter Source Apportionment Technology (PSAT) algorithm which allows the calculation of different source contributions to both primary and secondary particulate matter concentrations in the modeling domain. As an example, the aerosol age in the eastern United States, including both primary and secondary species, is examined using the regional CTM PMCAMx. The average calculated ages are on the order of a few days for particulate matter near the ground but are highly variable in space and time. Primary aerosol species had average ages of approximately $24 \mathrm{~h}$ over this polluted continental region while the average ages for secondary species were $48-72 \mathrm{~h}$ near the surface. As expected, the average age of all aerosol components increases vertically in the atmosphere. Age increases rapidly away from the sources of aerosol and its precursors, and for nonvolatile species it increases with particle size.

Citation: Wagstrom, K. M., and S. N. Pandis (2009), Determination of the age distribution of primary and secondary aerosol species using a chemical transport model, J. Geophys. Res., 114, D14303, doi:10.1029/2009JD011784.

\section{Introduction}

[2] Atmospheric particulate matter keeps evolving during its atmospheric lifetime. Particles grow by condensation and cloud processing, collide with other particles, undergo chemical and physical changes, may partially evaporate, and of course they are transported over often long distances. While aerosol properties and composition can be determined at the point of emission and at a certain location in the atmosphere, the time that it took the aerosol to travel between these points is in general unknown. During the analysis of field measurements, our inability to determine easily the time that the aerosol has spent in the atmosphere does not allow calculation of rates of change for different chemical and physical processes. Quantifying the age of the aerosol as a function of space and time can provide valuable insight into the characteristics of the aerosol that may be important for climate and health impacts. Aerosol age can be defined as the time that has elapsed since a particle (or its precursor) entered the atmosphere, thus making it different from aerosol lifetime (the average time that particulate matter is expected to persist in the atmosphere). Here we will not focus on the age of individual particles but rather on the age of individual aerosol components (primary organics, sulfate, secondary organics, etc).

\footnotetext{
${ }^{1}$ Department of Chemical Engineering, Carnegie Mellon University, Pittsburgh, Pennsylvania, USA.

${ }^{2}$ Department of Chemical Engineering, University of Patras, Patras, Greece.

Copyright 2009 by the American Geophysical Union. 0148-0227/09/2009JD011784
}

[3] There have been few efforts aimed at estimating the age of ambient aerosol due to the difficulty of this task. The lifetime of species is often calculated with global models as the burden over the total sinks for a species [Seinfeld and Pandis, 2006]. This gives an estimate of overall lifetime but not the age distribution or any temporal or spatial resolution. Most of the previous studies have attempted to estimate the age of gaseous pollutants, particularly volatile organic compounds, rather than aerosol species. Calvert [1976] used the ratios of measured concentrations of reactive hydrocarbons to acetylene to estimate $\mathrm{OH}$ concentrations in the atmosphere in Los Angeles. Nelson and Quigley [1983] later applied the approach to two reactive species by utilizing the ratio between $m$ - and $p$-xylene and ethylbenzene. This technique was later extended to estimate the "photochemical age" of an air mass [Roberts et al., 1984]. The "photochemical age" of an air mass is by its definition not the physical age of each species (i.e., how long since the pollutant, or its precursor, was emitted) but rather a measure of the extent of its chemical processing with respect to the hydroxyl radical. For this reason, the "photochemical age" does not increase when the $\mathrm{OH}$ concentrations are low such as during the nighttime [Cubison et al., 2006]. Studies have been carried out with a variety of hydrocarbon pairings to determine the "photochemical age," including toluene/benzene, ethylbenzene/ benzene, o-xylene/benzene [Roberts et al., 1984], light nonmethane hydrocarbons [Rudolph and Johnen, 1990], and benzene/toluene [de Gouw et al., 2005; Cubison et al., 2006]. Many of these studies have estimated photochemical ages on the order of several days for the hydrocarbons studied. 
[4] There are many implicit assumptions in this photochemical age calculation approach (also called a "photochemical clock"). The first is that both hydrocarbons used are only removed from the air mass by oxidation with the hydroxyl radical [Roberts et al., 1984; Volz-Thomas and Kolahgar, 2000] therefore neglecting reactions with other oxidants. Other essential assumptions are that the chosen hydrocarbons have the same sources, those sources have a constant composition with respect to those compounds and there is no injection of fresh emissions into the air mass downwind from the original source which would result in a decrease in the estimated "photochemical age" [Parrish et $a l ., 1992]$. Two further assumptions required by this approach are that the species have negligible background concentrations and there is no mixing of air masses with different photochemical ages [McKeen and Liu, 1993; McKeen et al., 1990; McKenna, 1997].

[5] The use of carbon isotopes in estimating the age of hydrocarbons is a relatively new approach first introduced by Rudolph and Czuba [2000]. This approach instead of using the differing rates of reactions between two hydrocarbons and $\mathrm{OH}$, relies on the differing rates of reaction for the different stable isotopic counterparts of the same hydrocarbon (e.g., studying the changes in the ratio of ${ }^{13} \mathrm{C}$ to ${ }^{12} \mathrm{C}$ in $n$-butane). This approach is based on the kinetic isotope effect which results in small differences in the reactivity of isotopic counterparts with $\mathrm{OH}$. It allows the estimation of the average age of each hydrocarbon separately. There have been a limited number of applications of this approach due to the lack of necessary field data [Rudolph and Czuba, 2000; Saito et al., 2002; Thompson et al., 2003]. This approach is sensitive to the variation in isotopic composition by source [Redeker et al., 2007] and the uncertainties in the calculated kinetic isotopic effects [Rudolph and Czuba, 2000]. There is also no direct corollary that can be used in the estimating of particulate matter age.

[6] There have been few modeling approaches to estimating the age of atmospheric pollutants. Kleinman et al. [2003] utilized a trajectory model to estimate the age of nonreactive particulate matter in the Phoenix, Arizona, area. In order to determine an age of the air mass, nonreactive particles were released into the model at ground level at a rate proportional to the $\mathrm{NO}_{\mathrm{x}}$ emission rate. The "particles" were grouped into $30 \mathrm{~min}$ long age bins and tagged to track when they were emitted. This gave an approximation of the age distribution for the nonreactive, primary particles in Phoenix with an average age of a few hours. They also calculated the age distribution by treating the inert "particles" as a mixture of reactive compounds that are removed by reaction with $\mathrm{OH}$ (using a variety of $k_{\mathrm{OH}}$ values similar to those for hydrocarbons) to compare the results to "photochemical age" results from hydrocarbon ratios in Phoenix, Arizona. Unfortunately, this modeling approach does not allow for the mixing of air masses with pollutants of different ages and also does not account for the age of secondary aerosol species. It also neglects the age of background aerosol in the air mass, looking at age of only particles emitted into the air mass in the modeled period.

[7] Stohl et al. [2003] proposed another modeling approach to study the age of mainly gaseous pollutants in the atmosphere. Using a Lagrangian trajectory model, a $\mathrm{CO}$ age distribution was determined by tagging emitted $\mathrm{CO}$ based on its release time. This calculated age distribution was used to study the intercontinental transport of pollutants. Parrish et al. [2007] extended this approach to estimate the age distribution of nonmethane hydrocarbons by implementing a simple chemical scheme in the model used by Stohl et al. [2003]. In this scheme, the tracers were exposed to a constant $\mathrm{OH}$ concentration and the different hydrocarbons were represented by tracers with differing $k_{O H}$ values. Parrish et al. [2007] then compared the ages calculated using the model to those calculated using the "photochemical clocks" approach concluding that the "photochemical clocks" were inaccurate when the air mass contained species with differing reactivities and emissions times. The major drawback of this approach is that it is not applicable to the determination of the age of particulate matter, especially secondary species and the simplified treatment of chemistry makes it inadequate for estimating the age of most reactive gas species.

[8] An approach that has long been applied to study the age of atmospheric aerosols is calculation of their atmospheric residence time based on decay of radioactive species in the particles. The most commonly used species are the daughters of ${ }^{226} \mathrm{Ra}$ decay: ${ }^{210} \mathrm{~Pb},{ }^{210} \mathrm{Bi}$, and ${ }^{210} \mathrm{Po}$. These are of interest because the decay product of ${ }^{226} \mathrm{Ra}$ is gaseous ${ }^{222} \mathrm{Rn}$ which is released in the atmosphere from the Earth's crust. ${ }^{222} \mathrm{Rn}$ then decays into ${ }^{210} \mathrm{~Pb}$ which condenses on aerosols in the atmosphere. After condensing, ${ }^{210} \mathrm{~Pb}$ will further decay into ${ }^{210} \mathrm{Bi}$ followed by ${ }^{210} \mathrm{Po}$ [Poet et al., 1972]. The ratio of ${ }^{210} \mathrm{Bi} /{ }^{210} \mathrm{~Pb}$ and ${ }^{210} \mathrm{Po} /{ }^{210} \mathrm{~Pb}$ in the aerosol can then be used to determine a residence time of primary aerosol in the atmosphere. In theory, the two ratios should give similar results for residence times but in reality, ${ }^{210} \mathrm{Bi}$ gives values of around 1 week [Fry and Menon, 1962; Poet et al., 1972] while ${ }^{210}$ Po gives values of up to a few months [Gaffney et al., 2004; Baskaran and Shaw, 2001]. This approach is very sensitive to sources of ${ }^{210} \mathrm{Po}$ other than ${ }^{222}$ Rn decay. Moore et al. [1976] studied the sources of ${ }^{210} \mathrm{Po}$ in the atmosphere and estimated that as much as $90 \%$ of the ${ }^{210} \mathrm{Po}$ is from sources other than the decay of ${ }^{222} \mathrm{Rn}$. The other sources include soil resuspension, coal burning power plants, forest fires, and plant exudates. These additional sources significantly increase the estimated residence time. Finally, this approach also assumes a constant flux of ${ }^{222} \mathrm{Rn}$ from the ground which is not true for air masses that have passed over the oceans [Moore et al., 1976]. Kuroda et al. [1978] took advantage of the 14th Chinese test on 18 March 1972 to study the residence time of ${ }^{90} \mathrm{Sr}$ in the atmosphere using the ratio of ${ }^{89} \mathrm{Sr}$ to ${ }^{90} \mathrm{Sr}$ in rainwater collected at Fayetteville, Arizona. These results were in agreement with calculations done using ${ }^{210} \mathrm{Po} /{ }^{210} \mathrm{~Pb}$.

[9] Most of the existing approaches cannot account for the changes in the age distribution of a pollutant as a result of the mixing of air masses with different age distributions. They are also sensitive to different sources, particularly their composition profiles. Also, none of these approaches allow for the calculation of a separate age distribution for each species or even the difference in the age distribution of primary and secondary aerosol species. One weakness that all the measurement-based approaches share is that they only allow the calculation of the age of a species at a given location and time. Three-dimensional CTMs have the potential to calculate these age distributions since these models 
already calculate the concentrations of all relevant pollutants for an entire region over a long time period. The use of a three-dimensional CTM will also account for mixing of air masses of differing ages and allow for the calculation of the age of secondary aerosol species.

[10] One approach that could be employed for the calculation of age in a CTM is to just track a large number of species tagged based on their emission time. An approach similar to this has been taken using the Source Oriented External Mixture model to estimate aerosol age in a Lagrangian transport model [Bhave et al., 2002]. Unfortunately, tracking of the age over any significant length of time with this approach would result in extremely large numbers of species in the model and unreasonable increases in computation time making this impractical for most applications. Our goal is to develop a computational efficient approach to track atmospheric aerosol age in a threedimensional CTM. Our proposed algorithm is based on the Particulate Matter Source Apportionment Technology (PSAT) described by Wagstrom et al. [2008] and allows the calculation of the age distribution for the particle matter mass as a function of location, time and species. We will describe first the approach used to determine the aerosol age, then evaluate it against a more direct approach, and then demonstrate the method by calculating the aerosol age for the eastern United States during a summer time period.

\section{Methods}

\subsection{Model Description}

[11] The three-dimensional CTM that was used for this study is PMCAMx [Gaydos et al., 2007] which is a research version of the publicly available CAMx (www.camx.com). The domain that was modeled was a $3492 \mathrm{~km} \times 3240 \mathrm{~km}$ region encompassing the Eastern United States using a $36 \mathrm{~km} \times 36 \mathrm{~km}$ grid. There were 14 vertical layers extending to $6 \mathrm{~km}$ used in this simulation. The time period studied was 12-22 July 2001 with 12 and 13 July not included in the analysis for model spin-up. The chemical mechanism used was the Carbon Bond Mechanism Version IV developed by Gery et al. [1989] which includes 34 gas phase species and 12 radical species. The model tracks 13 aerosol species and the aerosol size distribution is represented using the discrete size bin approach with 10 logarithmically spaced size bins from $40 \mathrm{~nm}$ to $40 \mu \mathrm{m}$. The bulk equilibrium approximation as described by Capaldo et al. [2000] is used for the simulation of aerosol condensation and evaporation. For this study, nucleation and coagulation were neglected because they have little effect on the aerosol mass distribution and the corresponding age distribution of PM components (on a mass basis). The meteorological inputs were created using MM5 [Grell et al., 1995] and the Lake Michigan Air Directors Consortium Base E emissions inventory (www.ladco.org) based on the EPA NEI 1999 inventory is used. Gases and primary particulate matter are emitted at every PMCAMx time step (5-15 min). Model performance for the period examined here has been extensively evaluated by Gaydos et al. [2007] and Karydis et al. [2007] and has been found to vary from fair to excellent for all $\mathrm{PM}_{2.5}$ components.

\subsection{Algorithm Description}

[12] The Particulate Matter Source Apportionment Technology (PSAT), which is described in detail by Wagstrom et al. [2008], allows for the computationally efficient tracking of source contributions in a CTM. PSAT is an algorithm that runs in parallel to the CTM using information passed from the model. The algorithm accounts for changes in the apportionment due to transport between neighboring cells, deposition, chemical reactions, and aerosol processes. PSAT utilizes the fact that at a given location and time, all the molecules of a particular species, regardless of their source, have the same probability of reacting, being transported or being deposited. This means that the total reaction rates and fluxes can be used to track the apportionment of different species from emission to final removal. The algorithm also tracks the source contributions to secondary species by utilizing the apportionment of the precursor gases. PSAT is computationally efficient and allows for the source categories to be defined in a variety of different ways. For this study two minor modifications were made to PSAT. Changes in apportionment resulting from vertical transport and turbulent mixing were calculated by solving for the changes in source contributions using the respective modules in PMCAMx. The second is that the fast reacting $\mathrm{NO}_{\mathrm{x}}$ and $\mathrm{NO}_{\mathrm{y}}$ species were treated as a family of compounds for the apportionment over gas phase chemistry with the changes in apportionment as a result of formation and destruction of $\mathrm{HONO}, \mathrm{HNO}_{3}$, PAN, and peroxy nitric acid being accounted for similar to the approach described by Yarwood et al. [2005].

[13] In order to utilize PSAT to track the aerosol age, the emissions are grouped into bins based on the time of emission; these will be referred to as emissions time periods (ETPs). Each of these ETPs is then treated as a source category by PSAT. For this study, the emissions have been assigned to bins of $24 \mathrm{~h}$ so all pollutants emitted on the first day of simulation are tracked computationally as "source 1," all pollutants emitted on the second day of simulation are tracked as "source 2," and similarly for all days of the simulation. The $24 \mathrm{~h}$ ETP is defined as being from 0000 to $2400 \mathrm{~h}$ Eastern Daylight Savings Time. Any time period (e.g., $1 \mathrm{~h}$ or half a day) can be used as the time unit for the calculation of the age distribution. The sensitivity of the calculated age distribution to the ETP length will be discussed in section 3.3.

[14] The age of secondary PM species can be calculated in principle either based on the time of emission of the corresponding precursor or based on the time of formation of the aerosol species. The former has been selected as the basis for this initial implementation of the algorithm because it reflects better the source-receptor linkages. This means that the age of sulfate will be based on when the $\mathrm{SO}_{2}$ that reacted to form it was emitted and not on when the sulfate was formed. The algorithm can be extended to calculate the age of secondary species based on the time of production with minor modifications. The identification of the time of formation is more complicated for semivolatile species as these are continually being transferred between the gaseous and condensed phases.

\subsection{Calculating the Average Age}

[15] Once the contributions from emissions from each ETP to the concentration at a particular location and time 


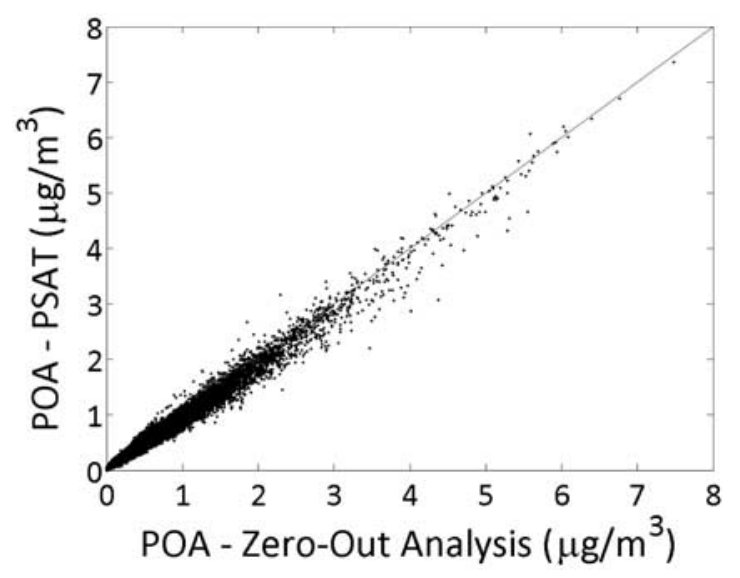

Figure 1. Comparison of contributions to primary organic aerosol concentrations from emissions on 12 July 2001 using Particulate Source Apportionment Technology (PSAT) and using zero-out analysis for all cells in the domain.

have been calculated, an average age can be calculated from this age distribution as a function of time. To do this, the age of the emission from a certain ETP is weighted by its contribution to the total concentration at a time, $t$. The emissions from each ETP are assigned to the middle of

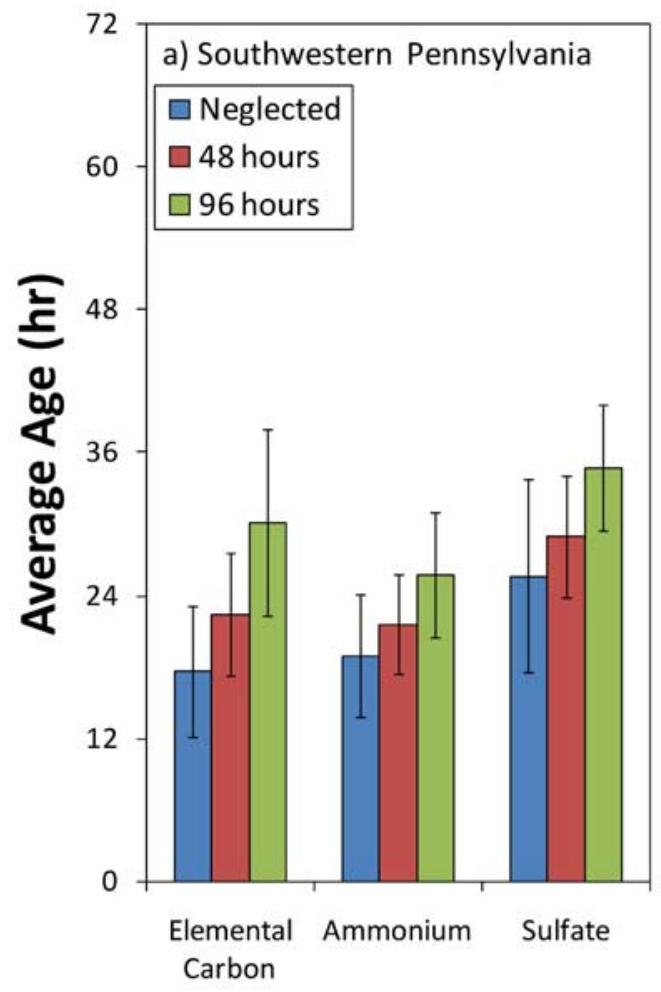

Species the corresponding period. Therefore, to calculate the age, Age $e_{\text {current }}$, of the emissions from the current ETP, we assume that

$$
\text { Age }_{\text {current }}=\frac{t^{*}}{2}
$$

where $t^{*}$ is the time elapsed in the current ETP. The age of aerosol emitted during prior ETPs of the simulation is calculated by

$$
\operatorname{Age}_{i}=t^{*}+\left(N_{i}-\frac{1}{2}\right) \Delta t
$$

where $A g e_{i}$ is the age for aerosol mass emitted in ETP $i, N_{i}$ is the number of ETPs that have elapsed since ETP $i$, and $\Delta t$ is the length of an ETP. The average age (Age $\left.e_{\text {average }}\right)$ can then be found as

$$
\text { Age }_{\text {average }}=\sum_{i} \frac{A g e_{i} c_{i}}{c_{\text {Total }}}
$$

where $c_{i}$ is the concentration resulting from emissions during ETP $i$ and $c_{\text {Total }}$ is the total concentration of that species in the particular location and time of interest.

[16] As an example, the periods of emission of the corresponding $\mathrm{SO}_{2}$ for sulfate at 1200 on 14 July 2001,

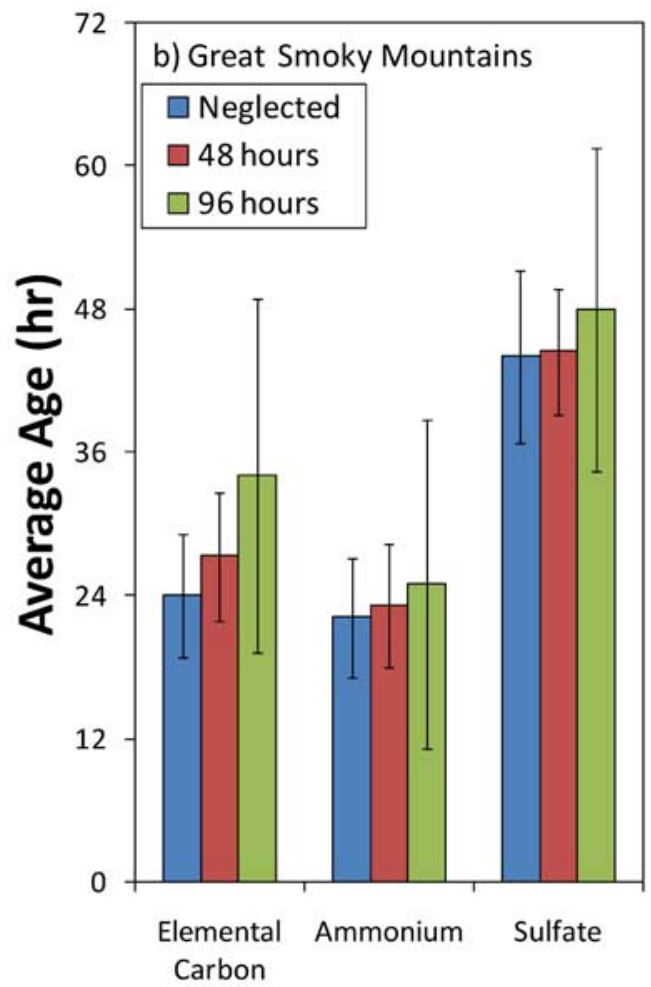

Species

Figure 2. Sensitivity of the average calculated age for elemental carbon (EC), sulfate, and ammonium depending on the age assigned to the boundary conditions for (a) southwestern Pennsylvania and (b) the Great Smoky Mountains at ground level for 14-22 July 2001. The error bars shown correspond to one standard deviation. 


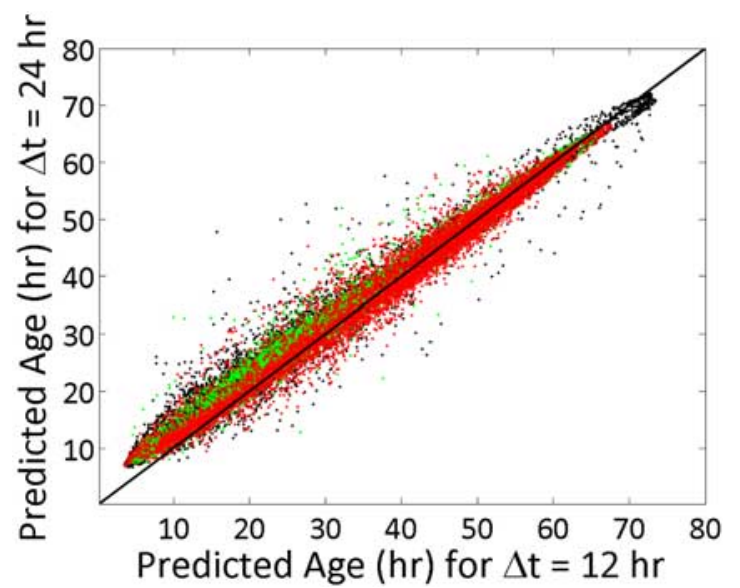

Figure 3. Daily average ages for EC (black), sulfate (red), and secondary organic aerosol (SOA) (green) calculated for 15 July 2001 when using a $24 \mathrm{~h}$ emissions time period (ETP) and a $12 \mathrm{~h}$ ETP for all ground level computational cells. Computational cells with boundary conditions contributions over $90 \%$ have been removed from this analysis.

the third day of simulation, in the Great Smoky Mountains are as follows: $0.8 \mu \mathrm{g} \mathrm{m}^{-3}$ from earlier on 14 July, $4.1 \mu \mathrm{g} \mathrm{m}^{-3}$ from 13 July, and $1.3 \mu \mathrm{g} \mathrm{m}^{-3}$ from 12 July. The sulfate produced from $\mathrm{SO}_{2}$ emitted during the third day of the simulation is assigned an average age of $6 \mathrm{~h}$ (from equation (1)). The average age of the sulfate from the first and second day of the simulation would be 48 and $24 \mathrm{~h}$, respectively (from equation (2)). Therefore the overall average sulfate age given these concentration distributions is $32 \mathrm{~h}$ (from equation (3)). For average ages calculated over a domain, a concentration weighted average is utilized in place of a straight land area average.

[17] One additional complication when calculating an average age for the aerosol in regional CTMs is what age to assign to the boundary conditions. For the base case calculations, the boundary conditions are neglected when calculating the average age. The sensitivity of the calculated average aerosol age to the age assigned to the boundary conditions is discussed in section 3.2.

\section{Evaluation and Sensitivity Analysis}

\subsection{Comparisons With Zero-Out Analysis}

[18] As an evaluation of the ability of the proposed algorithm to properly track the contributions from the emissions of a given day we performed the following test. The results for primary organic aerosol (POA) contributions from the first day of the simulation as calculated by this approach were compared to results given by just emitting the POA during the first day and assuming zero emissions during the rest of the simulation ("reverse zero-out analysis"). The comparison between the results of the two approaches for every hour and every grid cell is shown in Figure 1. These two approaches show good agreement with one another (in $83 \%$ of the cases the error is less than $10 \%$

\begin{tabular}{|l|r|}
\hline Boundary Conditions & July 17 \\
\hline July 12 & July 18 \\
\hline July 13 & July 19 \\
\hline July 14 & July 20 \\
\hline July 15 & July 21 \\
\hline July 16 & July 22 \\
\hline
\end{tabular}

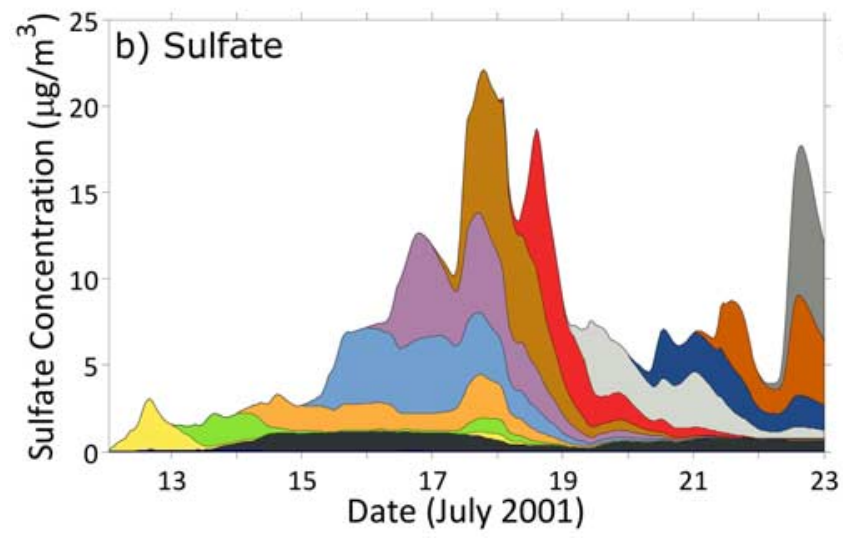

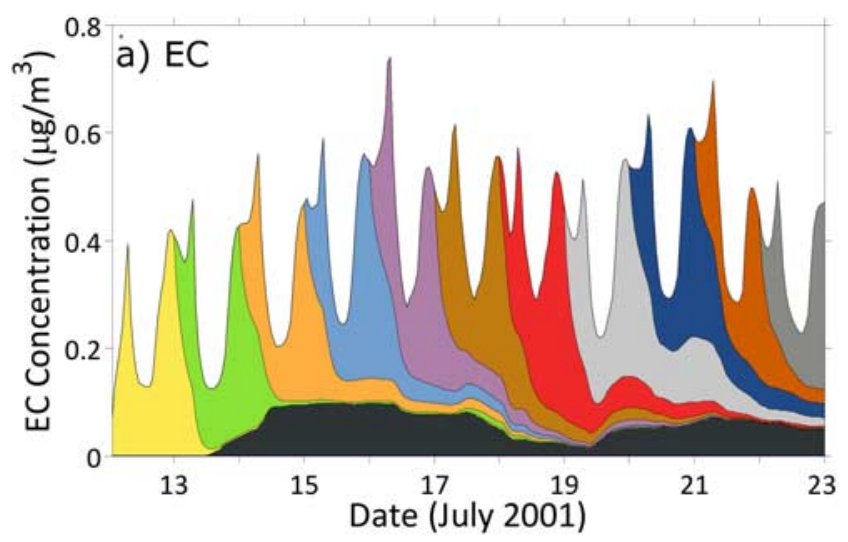

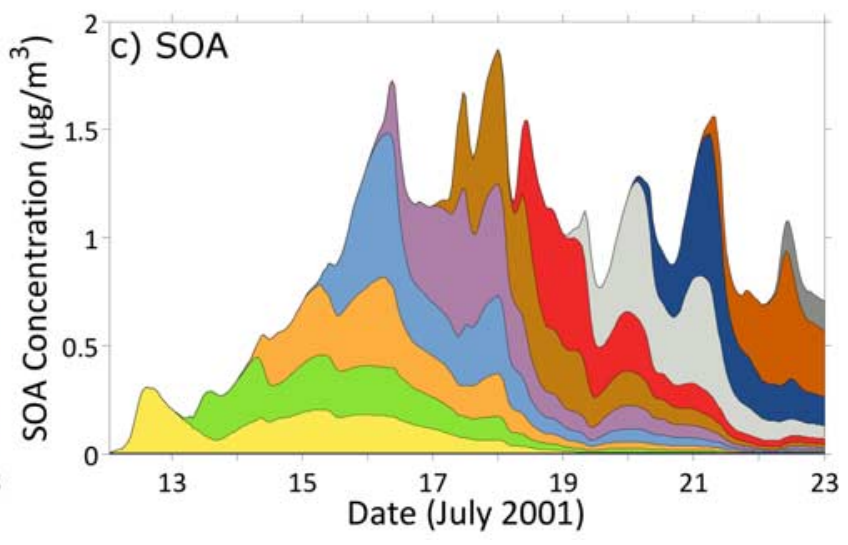

Figure 4. Age distribution at ground level in southwestern Pennsylvania for (a) EC, (b) sulfate, and (c) SOA. 


\begin{tabular}{|l|r|}
\hline Boundary Conditions & July 17 \\
\hline July 12 & July 18 \\
\hline July 13 & July 19 \\
\hline July 14 & July 20 \\
\hline July 15 & July 21 \\
\hline July 16 & July 22 \\
\hline
\end{tabular}
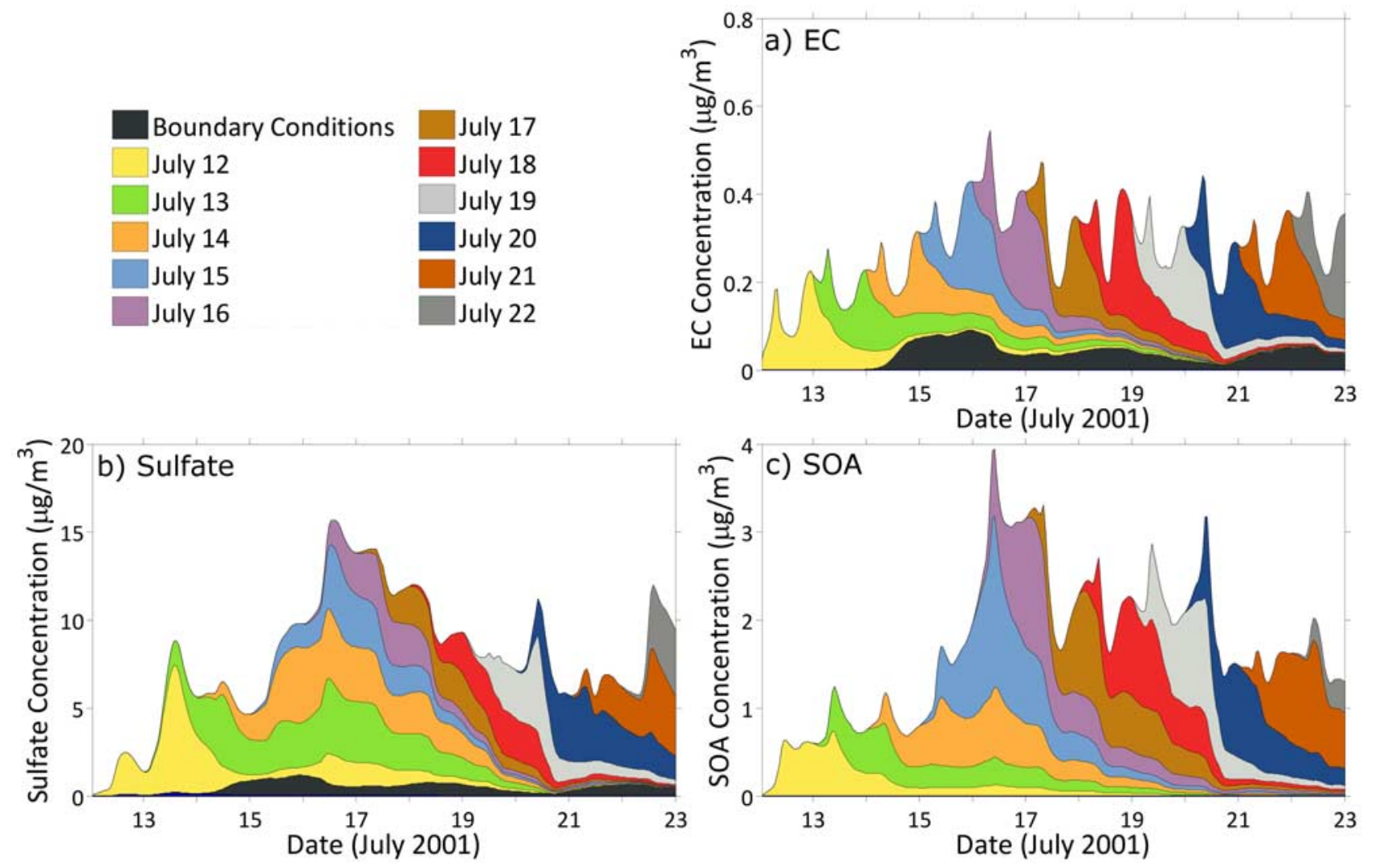

Figure 5. Age distribution at ground level in the Great Smoky Mountains for (a) EC, (b) sulfate, and (c) SOA.

and for $70 \%$ under $1 \%$ ), confirming that PSAT is able to properly track contributions from different periods of the simulation. The discrepancies are due to the linear treatment of the apportionment changes during the advection calculations by PSAT [Wagstrom et al., 2008] and small nonlinearities in other processes as a result of the change in the total aerosol distribution after the first day in the zero-out analysis. The advantages of PSAT over this "reverse zeroout analysis" approach are computational efficiency and the ability to track secondary species. Further evaluation of PSAT as a source apportionment algorithm was carried out by Wagstrom et al. [2008].

\subsection{Sensitivity to the Age of Boundary Conditions}

[19] As a test of the sensitivity of the calculated ages to the age assigned to the boundary and initial conditions, three cases were compared: (1) the boundary and initial conditions were neglected when calculating the average age; (2) they were assigned an age of 2 days (48 h); (3) they were assigned an age of 4 days $(96 \mathrm{~h})$. Figure 2 shows the average age in southwestern Pennsylvania and the Great Smoky Mountains for these three different scenarios. Southwestern Pennsylvania and the Great Smoky Mountains are defined as approximately $100 \times 100 \mathrm{~km}$ regions centered about $\left(40.4^{\circ},-79.8^{\circ}\right)$ and $\left(35.6^{\circ},-83.6^{\circ}\right)$, respectively. The impact on the ages calculated in the Great Smoky Mountains is small since there is little contribution of longrange transport of particulate matter in that region for this time period. The impact on the ages calculated in south- western Pennsylvania is greater since the region is closer to the northern boundary of the model domain. Elemental carbon (EC) ages have the greatest dependence on the age of the boundary conditions but the impact on particulate ammonium and sulfate is still nonnegligible. The greater impact on elemental carbon age is the result of higher relative contributions to elemental carbon from boundary conditions than for ammonium and sulfate. For this reason it is important to carefully consider the treatment of the age of boundary conditions when calculating the age of aerosol in a region using modeling techniques such as this, particularly in locations nearer to the edges of the domain. For simplicity, the average age calculated by neglecting the contributions from the boundary conditions to the age distribution is discussed in this paper. This is the age of the material emitted in the domain while the overall age is higher depending on the contribution of long-range transport and the age of the transported material.

\subsection{Sensitivity to the Discretization Time}

[20] Another concern is the sensitivity of the calculated age to the ETP length. For the base case results, a $24 \mathrm{~h}$ ETP was used. In order to test the sensitivity of the results to this choice the average age was recalculated calculated using a $12 \mathrm{~h}$ ETP. The calculated average ages using the two ETP lengths for EC, sulfate, and secondary organic aerosol (SOA) in all cells in the domain are shown in Figure 3. Approximately $80 \%$ of the calculated ages for EC are within $20 \%$ of one another for the two runs and more than $60 \%$ are 

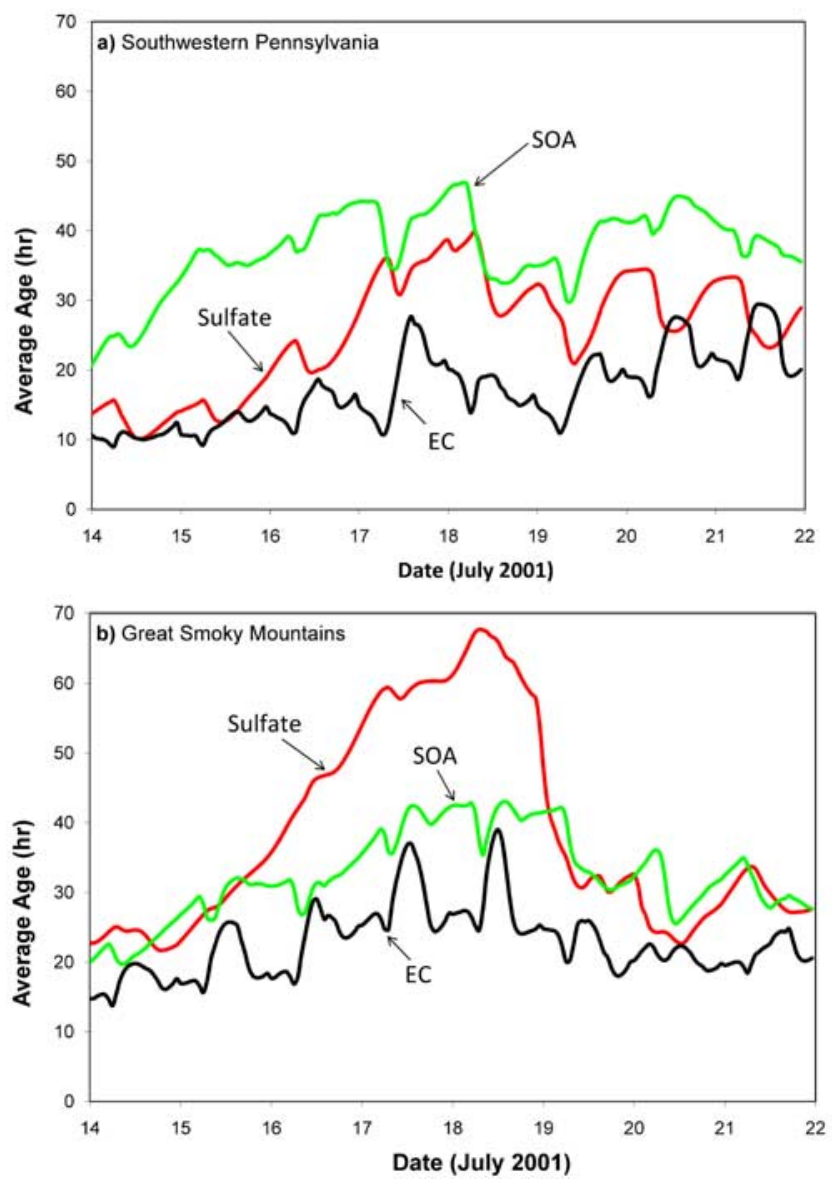

Figure 6. Age of EC, sulfate, and SOA at ground level as a function of time in two locations in the domain: (a) southwestern Pennsylvania and (b) Great Smoky Mountains.

within $10 \%$. Approximately $85 \%$ of the calculated ages are within $10 \%$ for sulfate and more than $70 \%$ are within $10 \%$ for SOA. The bias was $1.5 \mathrm{~h}, 0.1 \mathrm{~h}$, and $1.5 \mathrm{~h}$ for EC, sulfate, and SOA, respectively. EC showed the strongest sensitivity on the choice of the ETP length while sulfate was the least sensitive. This is a result of the higher bias at the lower age values (were many EC points are located) than the higher age values. The agreement between the results from both runs suggests that an ETP length of $24 \mathrm{~h}$ is sufficient for the purposes of this study due to its computational advantages.

[21] The aerosol age will also depend on the rates of different processes in the model, including wet and dry deposition and turbulent dispersion. The parameterizations used in PMCAMx for these processes are described on the CAMx Web site (www.camx.com). The sensitivity of PMCAMx to removal and other processes in the same domain has been analyzed by Dawson et al. [2007].

\section{Age of Aerosol Species}

\subsection{Age Distributions}

[22] Figures 4 and 5 show the age distribution at ground level for three representative aerosol species in southwest- ern Pennsylvania and the Great Smoky Mountains, respectively. The species shown represent the three major types of aerosols in the model: primary aerosol (EC), nonvolatile secondary aerosol (sulfate), and semivolatile secondary aerosol (SOA). In Figures 4 and 5, each color represents the contributions to the total concentration from the emissions from a different day of the simulation and the total is the predicted concentration of the species.

[23] The EC at ground level in southwestern Pennsylvania is relatively "young" with most of the contributions coming from the current or the prior day (Figure 4a). This $\mathrm{PM}$ is not necessarily local; some of it has been emitted in nearby areas and has been transported to the receptor area during these 1-2 days. There is also a nonnegligible contribution from the boundary conditions to the concentrations of $\mathrm{EC}$ in this region. The drastic daily decrease in $\mathrm{EC}$ concentration in the late morning is the result of the breakup of the nighttime boundary layer and the mixing with air from the free troposphere where EC levels are lower.

[24] The predicted age distribution for sulfate in southwestern Pennsylvania is shifted toward "older" aerosol compared to EC (Figure 4b), because the age of sulfate reflects the time since $\mathrm{SO}_{2}$ emission. This leads to an increase in the estimated age of the sulfate and an increase in the persistence of the contributions of emissions from those time periods. The age distribution for SOA in southwestern Pennsylvania at the ground level shows even higher contributions from past days than sulfate due to the relative distance of sources of VOCs versus $\mathrm{SO}_{2}$ for this site. The $\mathrm{SO}_{2}$ sources are closer to the southwestern Pennsylvania region than many of the large VOC sources (e.g., biogenic SOA precursors from the south or anthropogenic precursors from the midwest) resulting in older SOA than sulfate in the region.

[25] The EC age distribution in the Great Smoky Mountains is shifted toward "older" aerosol compared to EC in southwestern Pennsylvania (Figure 5a). This is due to higher local emissions of EC in the southwestern Pennsylvania area than in the Great Smoky Mountains. There are also greater contributions from emissions on earlier days in the time period to the sulfate concentrations in the Great Smoky Mountains when compared to southwestern Pennsylvania. This is also the result of the sources of sulfate and $\mathrm{SO}_{2}$ being nearer to southwestern Pennsylvania than the Great Smoky Mountains. The comparison of the age distribution of SOA between southwestern Pennsylvania and the Great Smoky Mountains yields different results from that for EC and sulfate. The SOA is actually "younger" in the Great Smoky Mountains. This is due to the fact that the Great Smoky Mountains are a large source of biogenic VOCs.

\subsection{Temporal Variability of Age}

[26] Figure 6 shows the age as a function of time for the three representative PM species in an urban and a rural location. The average age of an aerosol component in a particular location can be highly dependent on time. The diurnal pattern of the age of EC results from the increase in age as the nighttime boundary layer breaks up and the fresher emissions are mixed with the older EC from aloft. 


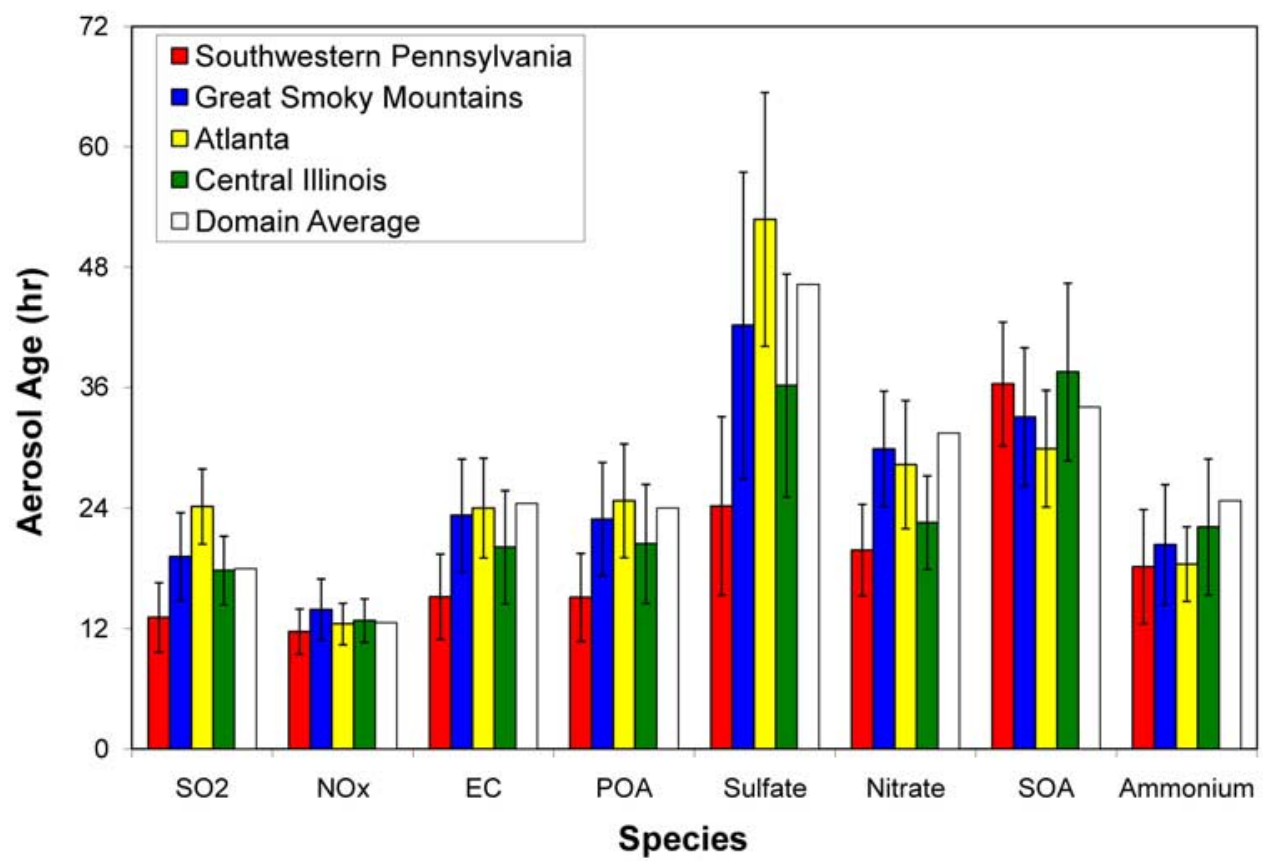

Figure 7. Average age at ground level for the major particulate matter species and their gaseous precursors at four locations in the domain and their domain-wide average age for 14-19 July 2001. The error bars show one standard deviation and are based on the hourly average age.

This results in a sudden increase in the perceived age of EC at the ground level.

[27] Southwestern Pennsylvania shows the least temporal variation in age of sulfate. This is due to the relative nearness of the $\mathrm{SO}_{2}$ source to the southwestern Pennsylvania region meaning most air masses passing through the region contain sulfate from relatively nearby sources. The Great Smoky Mountains show drastic changes in the sulfate age with time with ages ranging from $24 \mathrm{~h}$ to almost $72 \mathrm{~h}$ just within the simulation period. This is due to the different source regions for the air masses on these days so the sulfate is coming from further away during some periods of time than others.

\subsection{Interspecies Comparisons}

[28] Figure 7 shows the average age of the different aerosol species and selected gaseous precursors in the full domain at ground level and in four regions of interest, two rural (Great Smoky Mountains and central Illinois) and two urban (southwestern Pennsylvania and Atlanta, Georgia) sites. Atlanta and central Illinois, like the other two regions, are defined as approximately $100 \times 100 \mathrm{~km}$ regions centered about $\left(33.6^{\circ},-84.9^{\circ}\right)$ and $\left(40.1^{\circ},-89.1^{\circ}\right)$, respectively. Of the gaseous species, $\mathrm{NO}_{\mathrm{x}}$ has the smallest average age (approximately $12-15 \mathrm{~h}$ ) in all locations and over the entire domain at ground level because of its high reactivity. $\mathrm{SO}_{2}$ has a lower age near the large source areas such as southwestern Pennsylvania which is affected by the $\mathrm{SO}_{2}$ emitted by the power plants along the Ohio River and higher ages in areas far removed from these $\mathrm{SO}_{2}$ source regions such as Atlanta.

[29] Primary aerosol components have the lowest ages of all aerosol species in the model since additional time is needed for the production of the secondary compounds and their age is linked here to the time of emission of the precursor species. The lower age in southwestern Pennsylvania for EC and POA is the result of the significant emissions of primary aerosols from the southwestern Pennsylvania and nearby upwind areas.

[30] The species with the highest age is sulfate in almost all locations (with the exception of southwestern Pennsylvania). This higher age is the result of the lower reactivity of $\mathrm{SO}_{2}$ in comparison to other precursors (i.e., $\mathrm{NO}_{\mathrm{x}}$ ) thus resulting in longer $\mathrm{SO}_{2}$ residence times and higher ages for the corresponding secondary species. Also, since sulfate is nonvolatile, it remains in the condensed phase and is not subject to the additional removal mechanisms that semivolatile species such as nitrate and ammonium are subject to. Once again, southwestern Pennsylvania has the "youngest" sulfate due to the proximity of the Ohio River Valley and Atlanta has some of the "oldest" because there are few large $\mathrm{SO}_{2}$ sources in the immediate vicinity compared to the numerous large $\mathrm{SO}_{2}$ sources further north.

[31] As a result of the treatment of semivolatile species by PSAT, the age of semivolatile species (SOA, nitrate, and ammonium) will be the same for the condensable gas and corresponding semivolatile aerosol at a given location and time (i.e., at a particular time in Pittsburgh, Pennsylvania, the age of ammonia and ammonium will be the same). Nitrate has a lower age that is closer to that of the primary aerosol species than sulfate. This is the result of the combination of the lower $\mathrm{NO}_{\mathrm{x}}$ age and the semivolatile nature of particulate nitrate making it subject to rapid removal through both wet and dry deposition [Vayenas et al., 2005]. Particulate ammonium typically has slightly lower ages than nitrate because there is no oxidation step 

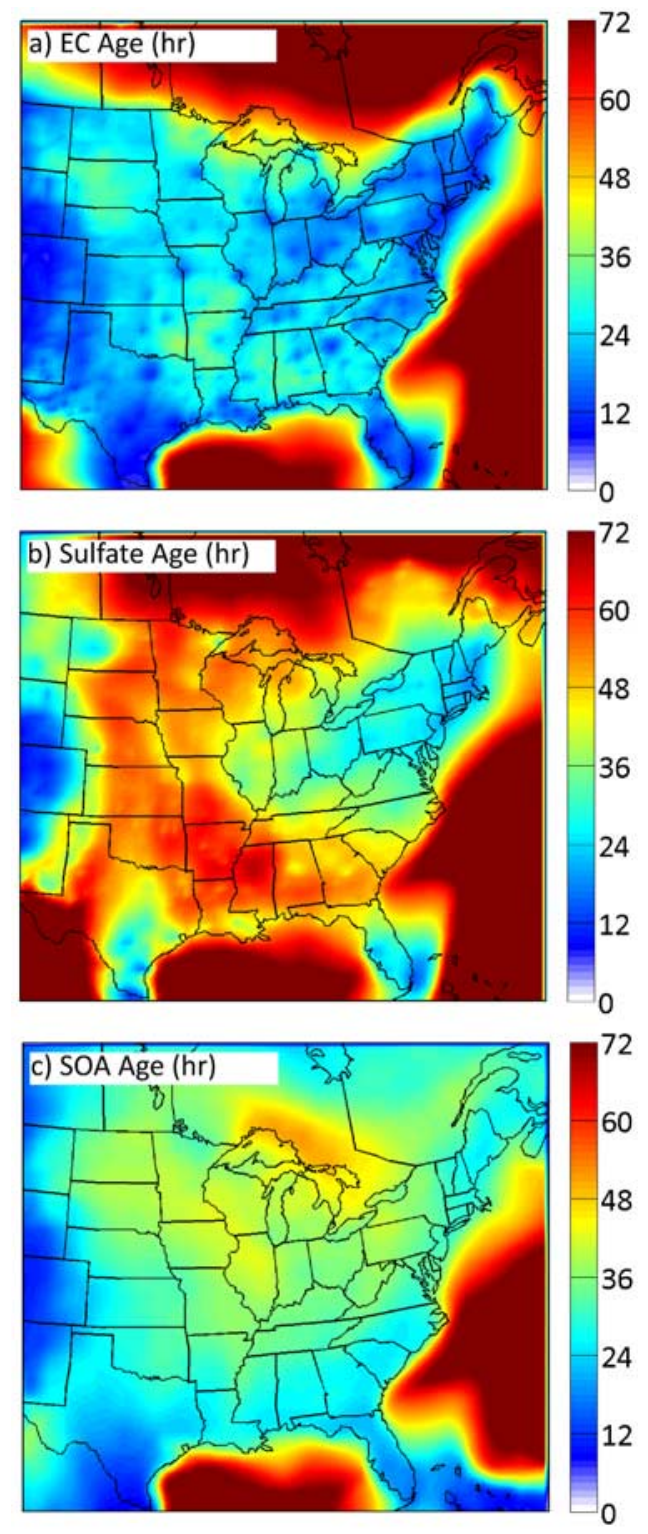

Figure 8. Average age (in hours) at ground level for (a) EC, (b) sulfate, and (c) SOA for 14-22 July 2001 based on the age of species emitted within the domain. The calculated ages near the edges of the domain can be strongly impacted by the age of the boundary conditions (not included in the graph).

for the conversion from the emitted gas to the condensable gas. This indicates that ammonium will be formed more quickly and therefore will be subject to aerosol removal mechanisms early in its life, resulting in average ages near those of primary particulate matter.

\subsection{Spatial Distribution of Age}

[32] Figure 8 shows the average age maps for EC, sulfate, and SOA at the ground level throughout the entire domain for the simulated period. The high average ages calculated near the northern, eastern, and southern edges of the domain are the result of a lack of emission sources in these regions being represented in the model. EC has an average age of around $12 \mathrm{~h}$ in areas near EC sources, primarily major cities.
Its average age is closer to $36 \mathrm{~h}$ in rural areas without any major cities nearby such as North and South Dakota, Oklahoma, Arkansas, and rural parts of Alabama and Mississippi. The highest values for average age over land were found in eastern Oklahoma and western Arkansas. Its average age increases to several days over the oceans.

[33] The sulfate average age spatial distribution is characterized by significant gradients. The average age of sulfate is highest in the western and southern areas of the domain, except coastal Texas, because of the lack of $\mathrm{SO}_{2}$ sources in those areas with the area with highest age being northern Mississippi. The average age is significantly lower in coastal Texas and New Orleans due to the oil refining and chemical processing along the Texas coast. The lower ages in the northeast and mid-Atlantic are the product of the transport of large amounts of $\mathrm{SO}_{2}$ emissions from the Ohio River Valley into these regions.

[34] SOA shows the smoothest spatial age distribution of the three species with the lowest ages in the southern states where biogenic VOC emissions are high, particularly in the summer, and higher ages in the northern areas where VOC emissions are significantly lower. The highest average ages over land for SOA were found to be just north of the Great Lakes for this time period.

\subsection{Vertical Age Distributions}

[35] The vertical average age profiles for EC, sulfate, and SOA in four locations, southwestern Pennsylvania, Great Smoky Mountains, Atlanta, and central Illinois, are shown in Figure 9. In all four locations the average age approaches $60 \mathrm{~h}$ at an altitude of $3 \mathrm{~km}$. The vertical profile in southwestern Pennsylvania shows a smaller vertical gradient for SOA than other species because the SOA in the region is older and therefore relatively well-mixed vertically by the time it reaches this region. EC and sulfate are significantly older aloft (a factor of 3 or more) than near the surface since these species are strongly impacted by ground sources nearer to the region than SOA. The gradients in the vertical profile of average age in the Great Smoky Mountains are smaller than those found in southwestern Pennsylvania. The sulfate found in this region is well mixed as indicated by the lack of change in the age of sulfate over the lowest kilometer. The sulfate in Atlanta is also well mixed with almost no vertical gradient in the average age. Atlanta shows a stronger gradient in the SOA age than southwestern Pennsylvania due to the nearby biogenic sources. The younger age of SOA compared to $\mathrm{EC}$ after about $250 \mathrm{~m}$ is a result of Atlanta emissions of EC decreasing the age of EC near the surface. Central Illinois seems to be influenced by few local sources so the gradients in the age profiles are modest with less variation between the ages of the different species.

\subsection{Age and Particle Size}

[36] The implementation of PSAT into PMCAMx allows the study of the aerosol species age as a function of aerosol size. The age of aerosol over the size distribution is shown in Figure 10 for EC, sulfate, and SOA for southwestern Pennsylvania. The variation in age over the size distribution for SOA is small. This is mainly the result of the continuous mass transfer of these semivolatile organic species between the gas and particulate phases. The use of the bulk 

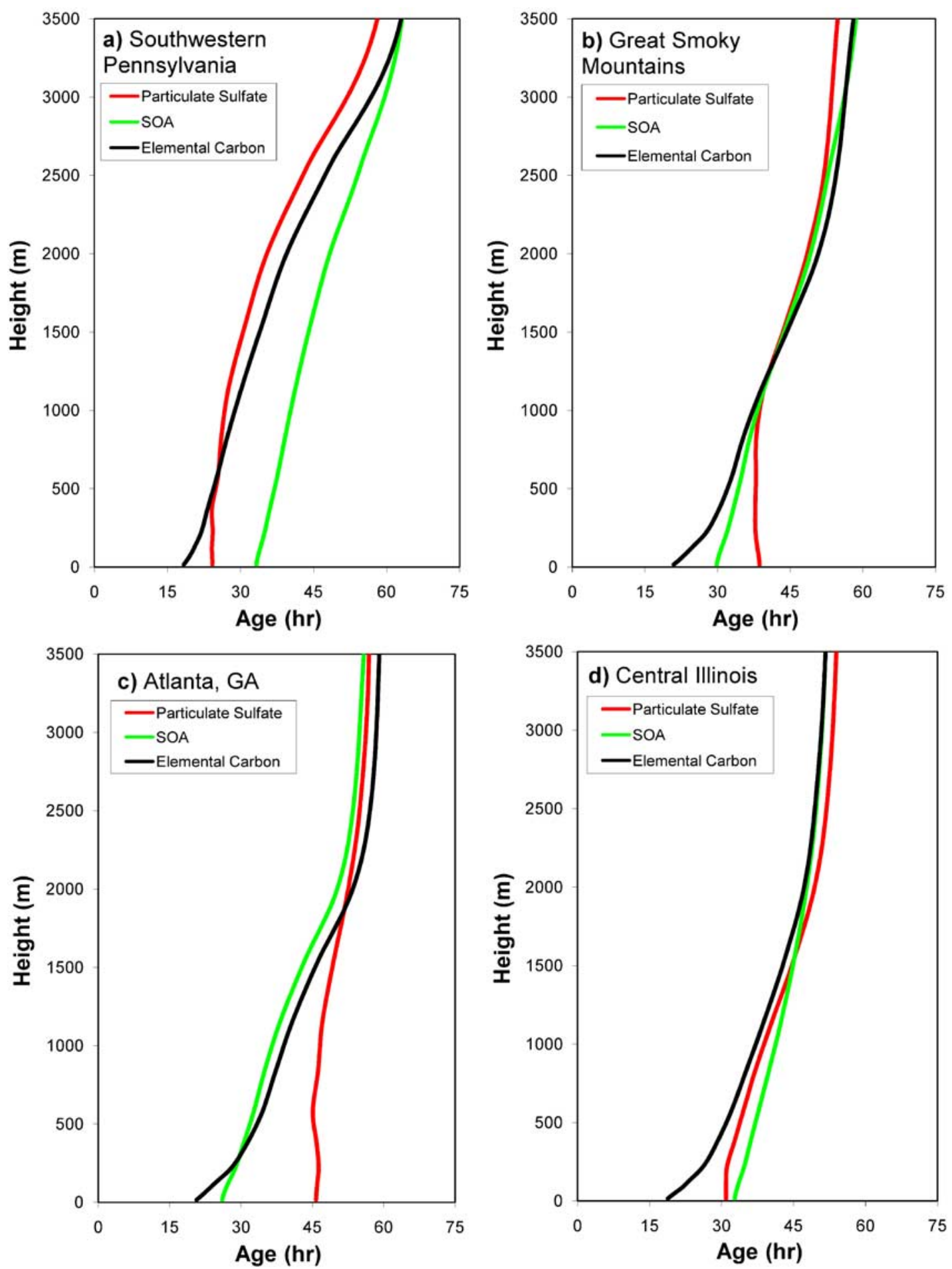

Figure 9. Average age of EC, sulfate, and SOA vertically for four locations: (a) southwestern Pennsylvania, (b) Great Smoky Mountains, (c) Atlanta, and (d) central Illinois for 14-19 July 2001.

equilibrium approximation for the organic thermodynamic calculations may also be contributing to this flat age distribution. The small difference is mainly due to the faster removal of the larger particles.

[37] EC emissions in the model are below $2.5 \mu \mathrm{m}$, therefore the only source of EC greater than $2.5 \mu \mathrm{m}$ is growth by condensation. As a result, the EC in these particles has been present in the atmosphere for an extended period of time (Figure 10a) and though the mass at these higher sizes is small, the age is higher than at smaller sizes. The higher age of particles around $200 \mathrm{~nm}$ is possibly the result of slower dry deposition in this size range. Finally, Figure 10b shows that sulfate has a significantly higher age at the larger particle sizes because of the growth of particles into these sizes through processes such as sulfuric acid condensation and cloud processing. One other minor factor 

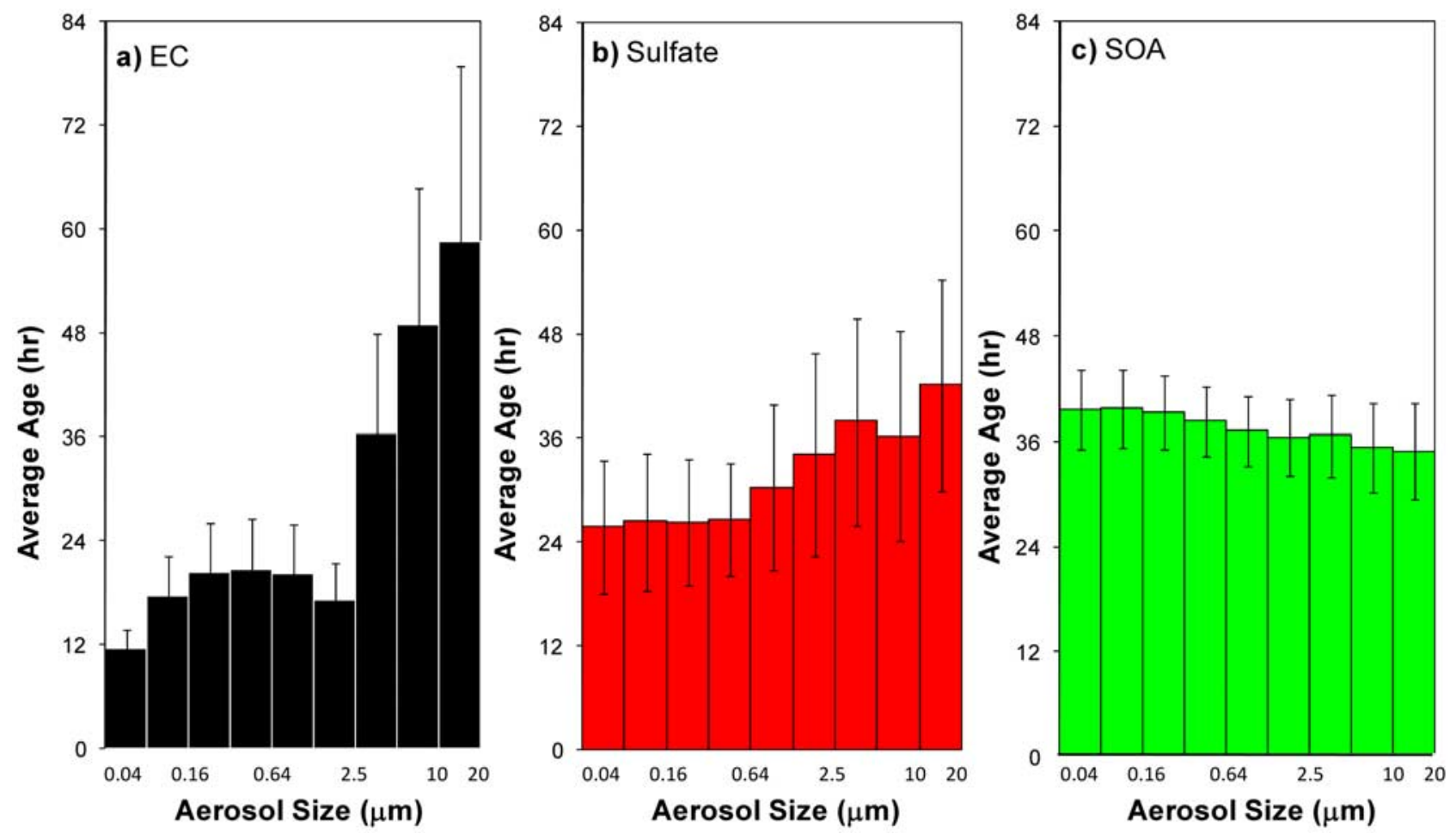

Figure 10. Average age of (a) EC, (b) sulfate, and (c) SOA in southwestern Pennsylvania as ground level as a function of the size of the aerosol for 14-22 July 2001. The error bars represent one standard deviation.

is the primary emissions of particulate sulfate in the size ranges below $2.5 \mu \mathrm{m}$.

\section{Computation Time}

[38] The implementation of this approach resulted in an increase in computation time of approximately $250 \%$ over the base model (before any tracking of the age distribution was implemented). This computational time is highly dependent on the number of ETPs and species to be tracked. The computation time for both the $24 \mathrm{~h}$ and $12 \mathrm{~h}$ ETP examples in section 3.3 were similar since a shorter time period was simulated in the $12 \mathrm{~h}$ and both approaches used about the same number of ETPs. This approach gave us estimates of the age distribution for any time, at any location (including vertically), and for any aerosol species contained in the model as a function of aerosol size. This makes this method a computationally efficient approach to calculate the aerosol age for a large area and over several days or weeks.

\section{Conclusions}

[39] The age of atmospheric aerosol in a region can be estimated using a three-dimensional CTM with relatively modest computational overhead. This analysis provides insights into the processes that are impacting the aerosol population. The ages found in the eastern United States during a summer period varied greatly by location, time, and species. The average age for EC was about $24 \mathrm{~h}$ while the average age of sulfate was around $48 \mathrm{~h}$. The higher ages for secondary species is the result of the choice to base the age of secondary species on the time of precursor emissions rather than the time of aerosol formation, another possible approach. The age was also shown to vary by a factor of $2-3$ at the same location depending on the period. This means that it is difficult to define an average age of a species in a region and the variation in calculated age between species at the same location and time makes it difficult to define an "age of the air mass" as is often done using the "photochemical age" approaches. The average age increases significantly with altitude, as expected, since it takes time for species to be transported vertically. This approach can also be applied to a variety of CTMs beyond PMCAMx, including global-scale models. Its use in these models is a way to estimate aerosol age without the complication of assigning an age to the boundary conditions. The ease of application of this approach to other CTMs is dependent on the details of the CTM in question and adjustments may need to be made for the transport calculations and to account for the chemical mechanism used, but the concept is applicable to a wide range of CTMs.

[40] Acknowledgments. This work was supported by the National Science Foundation (ATM-0732598) and the U.S. Environmental Protection Agency's STAR Graduate Fellowship Program. The authors thank Neil Donahue for his encouragement to work on this problem.

\section{References}

Baskaran, M., and G. E. Shaw (2001), Residence time of arctic haze aerosols using the concentrations and activity ratios of $\mathrm{Po}-210, \mathrm{~Pb}-210$ and Be-7, J. Aerosol Sci., 32, 443-452, doi:10.1016/S0021-8502(00)00093-8. Bhave, P. V., et al. (2002), Evaluation of an air quality model for the size and composition of source-oriented particle classes, Environ. Sci. Technol., 36, 2154-2163, doi:10.1021/es0112700. 
Calvert, J. G. (1976), Hydrocarbon involvement in photochemical smog formation in Los Angeles atmosphere, Environ. Sci. Technol., 10, 256262, doi:10.1021/es60114a003.

Capaldo, K. P., C. Pilinis, and S. N. Pandis (2000), A computationally efficient hybrid approach for dynamic gas/aerosol transfer in air quality models, Atmos. Environ., 34, 3617-3627, doi:10.1016/S13522310(00)00092-3.

Cubison, M. J., et al. (2006), The characterisation of pollution aerosol in a changing photochemical environment, Atmos. Chem. Phys., 6, $5573-$ 5588 .

Dawson, J. P., P. J. Adams, and S. N. Pandis (2007), Sensitivity of $\mathrm{PM}_{2.5}$ to climate in the Eastern US: A modeling case study, Atmos. Chem. Phys., 7, 4295-4309.

de Gouw, J. A., et al. (2005), Budget of organic carbon in a polluted atmosphere: Results from the New England Air Quality Study in 2002, J. Geophys. Res., 110, D16305, doi:10.1029/2004JD005623.

Fry, L. M., and K. K. Menon (1962), Determination of tropospheric residence time of lead-210, Science, 137, 994-995, doi:10.1126/ science.137.3534.994.

Gaffney, J. S., et al. (2004), Natural radionuclides in fine aerosols in the Pittsburgh area, Atmos. Environ., 38, 3191-3200, doi:10.1016/j.atmosenv. 2004.03.015

Gaydos, T. M., et al. (2007), Development and application of a threedimensional aerosol chemical transport model, PMCAMx, Atmos. Environ., 41, 2594-2611, doi:10.1016/j.atmosenv.2006.11.034.

Gery, M. W., et al. (1989), A photochemical kinetics mechanism for urban and regional scale computer modeling, J. Geophys. Res., 94, 12,92512,956, doi:10.1029/JD094iD10p12925.

Grell, G. A., J. Dudhia, and D. R. Stauffer (1995), A description of the fifthgeneration Penn State/NCAR Mesoscale Model (MM5), Tech. Note NCAR/TN-398 + STR, Natl. Cent. for Atmos. Res., Boulder, Colo.

Karydis, V. A., et al. (2007), Evaluation of a three-dimensional chemical transport model (PMCAMx) in the eastern United States for all four seasons, J. Geophys. Res., 112, D14211, doi:10.1029/2006JD007890.

Kleinman, L. I., et al. (2003), Photochemical age determinations in the Phoenix metropolitan area, J. Geophys. Res., 108(D3), 4096, doi:10.1029/2002JD002621.

Kuroda, P. K., et al. (1978), Atmospheric residence times of Sr-90 and $\mathrm{Pb}-$ 210, J. Radioanal. Chem., 43, 443-450, doi:10.1007/BF02519505.

McKeen, S. A., and S. C. Liu (1993), Hydrocarbon ratios and photochemical history of air masses, Geophys. Res. Lett., 20, 2363-2366, doi:10.1029/93GL02527.

McKeen, S. A., et al. (1990), On the indirect determination of atmospheric $\mathrm{OH}$ radical concentrations from reactive hydrocarbon measurements, J. Geophys. Res., 95, 7493-7500, doi:10.1029/JD095iD06p07493.

McKenna, D. S. (1997), Analytic solutions of reaction diffusion equations and implications for the concept of an air parcel, J. Geophys. Res., 102, 13,719-13,725, doi:10.1029/96JD03658.

Moore, H. E., et al. (1976), Source of polonium-210 in atmosphere, Environ. Sci. Technol., 10, 586-591, doi:10.1021/es60117a005.

Nelson, P. F., and S. M. Quigley (1983), The m-p-xylenes:ethylbenzene ratio-A technique for estimating hydrocarbon age in ambient atmospheres, Atmos. Environ., 17, 659-662, doi:10.1016/0004-6981(83) 90141-5.
Parrish, D. D., et al. (1992), Indications of photochemical histories of Pacific air masses from measurements of atmospheric trace species at Point Arean, California, J. Geophys. Res., 97, 15,883-15,901.

Parrish, D. D., et al. (2007), Effects of mixing on evolution of hydrocarbon ratios in the troposphere, J. Geophys. Res., 112, D10S34, doi:10.1029/ 2006JD007583.

Poet, S. E., H. E. Moore, and E. A. Martell (1972), Lead-210, bismuth-210, and polonium-210 in the atmosphere: Accurate ratio measurement and application to aerosol residence time determination, J. Geophys. Res., 77, 6515-6527, doi:10.1029/JC077i033p06515.

Redeker, K. R., et al. (2007), Isotope values of atmospheric halocarbons and hydrocarbons from Irish urban, rural, and marine locations, J. Geophys. Res., 112, D16307, doi:10.1029/2006JD007784.

Roberts, J. M., et al. (1984), Measurements of aromatic hydrocarbon ratios and NOx concentrations in the rural troposphere-Observation of air mass photochemical aging and NOx removal, Atmos. Environ., 18, 24212432, doi:10.1016/0004-6981(84)90012-X.

Rudolph, J., and E. Czuba (2000), On the use of isotopic composition measurements of volatile organic compounds to determine the "photochemical age" of an air mass, Geophys. Res. Lett., 27, 3865-3868, doi:10.1029/2000GL011385.

Rudolph, J., and F. J. Johnen (1990), Measurements of light atmospheric hydocarbons over the Atlantic regions of low biological activity, J. Geophys. Res., 95, 20,583-20,591, doi:10.1029/JD095iD12p20583.

Saito, T., et al. (2002), Stable carbon isotopic compositions of light hydrocarbons over the western North Pacific and implication for their photochemical ages, J. Geophys. Res., 107(D4), 4040, doi:10.1029/ 2000JD000127.

Seinfeld, J. H., and S. N. Pandis (2006), Atmospheric Chemistry and Physics, 2nd ed., John Wiley, Hoboken, N. J.

Stohl, A., et al. (2003), A backward modeling study of intercontinental pollution transport using aircraft measurements, J. Geophys. Res., 108(D12), 4370, doi:10.1029/2002JD002862.

Thompson, A., J. Rudolph, F. Rohrer, and O. Stein (2003), Concentration and stable carbon isotopic composition of ethane and benzene using a global three-dimensional isotope inclusive chemical tracer model, J. Geophys. Res., 108(D13), 4373, doi:10.1029/2002JD002883.

Vayenas, D. V., et al. (2005), Simulation of the thermodynamics and removal processes in the sulfate-ammonia-nitric acid system during winter: Implications for PM2.5 control strategies, J. Geophys. Res., 110, D07S14 doi:10.1029/2004JD005038.

Volz-Thomas, A., and B. Kolahgar (2000), On the budget of hydroxyl radicals at Schauinsland during the Schauinsland Ozone Precursor Experiment (SLOPE96), J. Geophys. Res., 105, 1611-1622, doi:10.1029/ 1999JD901046.

Wagstrom, K. M., et al. (2008), Development and application of a computationally efficient particulate matter apportionment algorithm in a threedimensional chemical transport model, Atmos. Environ., 42, 5650-5659, doi:10.1016/j.atmosenv.2008.03.012.

Yarwood, G., et al. (2005), Development of the CAMx Particulate Source Apportionment Technology (PSAT): Final report to Lake Michigan Air Directors Consortium, 91 pp., ENVIRON Int. Corp., Novato, Calif.

S. N. Pandis and K. M. Wagstrom, Department of Chemical Engineering, Carnegie Mellon University, 5000 Forbes Avenue, Pittsburgh, PA 15213, USA. (spyros@andrew.cmu.edu) 